This is the post print version of the article, which has been published in Journal of Cleaner

Production. 2018, 195, 102-110. https://doi.org/10.1016/j.jclepro.2018.05.202

This document has been downloaded from TamPub.uta.fi The Insitutional Repository of University of Tampere

\title{
Creativity, aesthetics and ethics of food waste in social media campaigns
}

\author{
Elina Närvänen ${ }^{1}$ \\ University of Tampere, Faculty of Management, Finland \\ elina.narvanen@uta.fi \\ Nina Mesiranta \\ University of Tampere, Faculty of Management, Finland \\ nina.mesiranta@uta.fi \\ Ulla-Maija Sutinen \\ University of Tampere, Faculty of Management, Finland \\ ulla-maija.sutinen@uta.fi \\ Malla Mattila \\ University of Tampere, Faculty of Management, Finland \\ malla.mattila@uta.fi
}

\begin{abstract}
A majority of food waste in developed countries is caused by households. Previous studies have focussed on explicating reasons and contexts for food waste, whereas consumer-oriented solutions still need further study. This study investigated how sociocultural meanings of household food waste reduction were negotiated in social media campaigns. It adopted an interpretive approach through a qualitative case study and utilised interviews and online materials as data. The study identified three sociocultural themes, creativity, aesthetics and ethics of food waste, interlinked through connections with food, waste and social media. The analysis elaborated how these three broader positive sociocultural meanings were used in the studied social media campaigns to (re)negotiate the food waste phenomenon. The paper proposes that highlighting positive meanings of food waste which resonate with consumers and facilitating consumer-to-consumer communications are potential ways to address sustainability issues.
\end{abstract}

Keywords: food waste, social media, sociocultural, consumer, campaign, qualitative case study

\footnotetext{
${ }^{1}$ corresponding author
} 


\section{Introduction}

Household food waste is often considered the most problematic type of food waste, not only because of its volume (Parfitt et al., 2010) but because it can also be considered a waste of all resources, such as water, through earlier parts of the value chain (Ridoutt et al., 2010). Reducing household food waste has recently gained momentum both politically (European Commission, 2016) and in research (Aschemann-Witzel et al., 2017, 2015; Hebrok \& Boks, 2017; Principato et al., 2015; Secondi et al., 2015; Young et al., 2017).

Previous studies have focussed on explaining why food waste emerges in households (Evans, 2012, 2011) and the nature and composition of household food waste (Hanssen et al., 2016; Jörissen et al., 2015; Katajajuuri et al., 2014). Demographic factors including education level and gender, attitudinal and behavioural patterns related to food waste and the degree of concern regarding the issue have also been identified as influencing food-waste behaviours (Principato et al., 2015; Secondi et al., 2015). Some studies have argued that while consumers may have positive attitudes towards reducing waste, the actual problem is difficult to address, because it links to factors including consumer lifestyles, habits and beliefs about food provisioning, planning, shopping and storage (Parizeau et al., 2015; Stancu et al., 2016; Stefan et al., 2013). For instance, Aschemann-Witzel et al. (2015) argued that more than just mere motivation to reduce food waste, consumers' skills in food provisioning and handling, or making trade-offs between priorities played roles in food-waste behaviour. Accessibility and convenience were argued as more relevant than information and education in attempting to change behaviour patterns (Bernstad, 2014). However, previous research has focussed on generating knowledge of the problem rather than on possible solutions (Hebrok and Boks, 2017).

In many consumer campaigns, food waste has continued to be framed negatively as an environmental problem, highlighting consumers' individual duty and obligation to change behaviour (Evans, 2011). However, studies have shown that people usually have strong reactions to food waste compared to other types of waste (Gjerris and Gaiani, 2013). People do not want to waste food, and it evokes feelings of guilt (Blichfeldt et al., 2015; Evans, 2012) together with environmental concern (Qi and Roe, 2016). It has been suggested that the reason for strong negative reactions arises at the existential level, where food waste is experienced as disrespectful. Food represents both a physical and symbolic link between humans and nature (Gjerris and Gaiani, 2013). Hence, as Evans (2012) argued, consumers are not careless about wasting food. For instance, consumers' intention to eat in a healthy way and provision their family might intersect with their intention to avoid waste; these are not always compatible (see 
e.g. Porpino et al., 2016, 2015).

According to one recent study, success factors of consumer-oriented campaigns directed at reducing household food waste included collaboration with other organisations, timing, involvement of people with the right competencies, managing attention and achieving large audiences (Aschemann-Witzel et al., 2017). One issue found important in these initiatives was a positive focus, which can be viewed as a facilitator of motivation. Although positive aspects were encouraged in previous research (Aschemann-Witzel et al., 2017; Gjerris and Gaiani, 2013), further research is needed into how these can be implemented. Researchers have also recommended focusing more on social and cultural contexts, norms and values as well as everyday conditions in which food is provisioned (Evans, 2011; Hebrok and Boks, 2017). This orientation suggests putting more emphasis on sociocultural aspects of consumption - how consumers actively construct and reconstruct as well as negotiate symbolic meanings related to food waste in everyday life (Moisander and Valtonen, 2006). From this perspective, consumers are not perceived merely as passive recipients of information but rather as active participants in meaning creation. The meanings created and recreated through language and other symbolic structures (e.g. images) play an important role in how people understand and interpret the world and themselves (Berger and Luckmann, 1984).

Social media is an increasingly important platform where consumers share information, interact and negotiate meaning. Research has also begun investigating the potential of using social media in sustainability campaigns (for a review, see Pearson et al., 2016). However, only a few studies so far have focussed on using social media in food waste reduction campaigns (Comber and Thieme 2013; Young et al., 2017). The purpose of this study is to investigate how sociocultural meanings of household food waste reduction are negotiated in social media campaigns. Food waste reduction provides an interesting context for studying sustainability campaigns in social media. Food has positive meanings for people, while waste is associated with something negative and unwanted. This paper aims to contribute to the literature stream related to using social media in sustainability campaigning as well as to research related to household food waste by focusing on the content of consumer-oriented food waste reduction campaigns rather than characteristics of the channels or objective success factors of different approaches. 


\section{Theoretical framework}

\subsection{Addressing sustainability issues through social media}

It is impossible to disregard the current role and impact of social media. Social media refers to 'a group of Internet-based applications which build on the ideological and technological foundations of Web 2.0, and which allow the creation and exchange of User Generated Content' (Kaplan and Haenlein, 2010, p. 61). Statistically, one-third of the global population and $71 \%$ of Internet users use social media regularly (eMarketer, 2017). It offers valuable opportunities for engagement, interactivity and dialogue, suggesting that these opportunities provide potential for organisations' communication and shareholder management (Lovejoy and Saxton, 2012). Utilising social media is crucial for commercial companies (Kaplan and Haenlein, 2010); non-profit organisations and public actors have also started realising social media's potential when aiming at different kinds of social goals (see e.g. Lovejoy and Saxton, 2012). For instance, different health organisations have seen social media's potential for improving people's health (see e.g. Korda and Itani, 2013). When the world's most popular social media platform, Facebook, reached two billion monthly users in June 2017, company CEO Mark Zuckerberg highlighted the platform's responsibility over issues such as climate change (Chaykowski, 2017).

Social media contributes to sustainability in many ways, such as providing platforms for social activism and information sharing as well as supporting sustainable business practices and addressing sustainability issues in companies' business practices (Pearson et al., 2016). Burchell et al. (2013) stated that campaigns aiming at encouraging new types of social norms related to sustainable consumption increasingly rely on digital technologies and social media. Social media allows existing social norms to be made visible, creating potential to attract the wider public's interest in sustainability issues and consequently to drive pro-environmental change at individual and structural levels (Pearson et al., 2016).

For consumers, social media platforms offer arenas to publicly document, articulate and scrutinise everyday sustainable living, i.e. consumption choices and practices, often aiming to motivate and control themselves (Haider, 2016; Sörum \& Fuentes, 2017). As Sörum and Fuentes (2017) pointed out, social media technologies can thus be considered Foucauldian 'technologies of the self,' helping consumers learn self-control and self-management. Short individual consumer narratives on sustainable consumption in social media create 'an online ecology of information' (Haider, 2016, p. 477) which shapes and is shaped by sustainable consumption-related collective norms and values. With neoliberalist thinking increasingly 
assigning responsibility to consumers for solving sustainability issues, consumer activities in social media can also be considered new forms of political consumerism, where sharing individual and private consumer acts become not only public but also collective and political (see Haider, 2016; Stolle and Micheletti, 2013; Sörum and Fuentes, 2017).

Researchers hold different viewpoints on social media's ability to affect food waste levels. Young et al. (2017), together with a large British grocery retailer, studied what types of interventions had the strongest effect on consumers' food waste behaviour. They claimed that for greater effect, conventional media should be used in the interventions instead of social media. However, this study has raised some criticism, and further inquiry is still needed on the potential of social media in helping solve the food waste problem (Grainger and Steward, 2017). In terms of food waste reduction, different types of social media interventions have been studied. Comber and Thieme (2013) conducted a study evaluating the use of BinCam (camera placed in consumers' bin, where the view was posted on Facebook) and found that triggering a self-reflection process had particular impact on consumers' food waste behaviour. Despite these efforts, research on affecting food waste levels through social media remains scarce and narrow. Previous studies have focussed on objective effects of different initiatives and interventions, while less research has examined their message content. Earlier research on social media and food waste has also concentrated more on interventions initiated by policy-makers or researchers (see Pearson et al., 2016) instead of examining consumer-to-consumer discussion.

\subsection{Reducing household food waste}

Previous research has produced contradictory results regarding the possibilities of affecting food waste levels. On one hand, some have suggested that campaigns aiming at reducing consumer food waste should concentrate on transforming consumers' everyday practices instead of trying to affect intentions or attitudes (Stefan et al., 2013). On the other hand, some have also argued that increasing consumers' perceived behavioural control over wasting food could have a positive effect (Koivupuro et al., 2012; Visschers et al., 2016). Mourad (2016) went further, calling for a focus on 'strong prevention', necessitating reassessment of the whole food system and power relationships connected to it.

Many initiatives have been established around the food waste issue (see Secondi et al., 2015). Aschemann-Witzel et al. (2017) studied the success elements of initiatives focussing on consumer-related food waste. They divided the initiatives into three types, according to the supply chain parts they interacted with: information and capacity-building initiatives, redistribution initiatives, and retail and supply chain-alteration initiatives. There has also been 
research on design interventions, mostly focusing on packaging-, refrigerator-, and freezerrelated innovations (for a review, see Hebrok and Boks, 2017).

Gjerris and Gaiani (2013) suggested three strategies employed by initiatives aiming to reduce food waste: knowledge transfer, moralising and presenting new narratives of the good life. The first strategy has been common in food waste campaigns, especially governmental interventions (Hebrok and Boks, 2017). However, knowledge transfer does not always lead to actions (Gjerris and Gaiani, 2013). The second strategy views consumers as passive subjects who need to learn and adopt externally supplied normative standards to act more ethically or sustainably (Cherrier, 2005). According to Qi and Roe (2016), households express guilt related to food waste behaviour as well as concern over food safety and freshness related to consuming food past the expiry date. Also, the 'good provider identity' is one of the strongest barriers to reducing food waste; that is, consumers believe that in using leftovers, they could risk their family's well-being or health (Graham-Rowe et al., 2014). The third strategy calls for approaching food waste positively, including joy, appreciation and a relationship with nature (Gjerris and Gaiani, 2013). Aschemann-Witzel et al. (2017) also demonstrated the importance of humour and the appreciation of food in successful initiatives; focussing on positivity also meant not moralising consumers about negative effects of food waste.

\subsection{Sociocultural meanings of food waste}

This study builds on the cultural perspective of consumption as a symbolic activity (Arnould and Thompson, 2005; Moisander and Valtonen, 2006). Culture is perceived to permeate all aspects of human life, helping people make sense of the world and themselves in it. Culture is constantly produced and reproduced, contested and negotiated in the everyday lives of its members (Hall, 1997). Consumption, on the other hand, is a thoroughly culturally constructed activity, both maintaining and recreating social and cultural meanings, values and everyday consumption practices (Moisander and Valtonen, 2006).

Prevailing sociocultural meanings guide and constrain the way people make sense of their everyday lives and how they engage in related consumption practices. Thus, these meanings make certain kinds of consumption patterns and interpretations more likely than others (Arnould and Thompson, 2005). However, consumers do not just passively reproduce cultural meanings but also actively transform and negotiate them in their daily lives. This meaning-production process also occurs in the market and by other actors, including companies and organisations (Moisander and Valtonen, 2006). These meanings are also shared and continuously negotiated in social media platforms (e.g. Rokka and Moisander, 2009). To 
change perceptions of food waste, actors must reinterpret and renegotiate the sociocultural meanings related to it. This was the process of interest for this particular study, focussing especially on three broader sociocultural meanings: creativity, aesthetics and ethics. These meanings were selected because they variously connect the topics of food and waste as well as social media. Figure 1 depicts how these meanings were interrelated in the framework of this study.

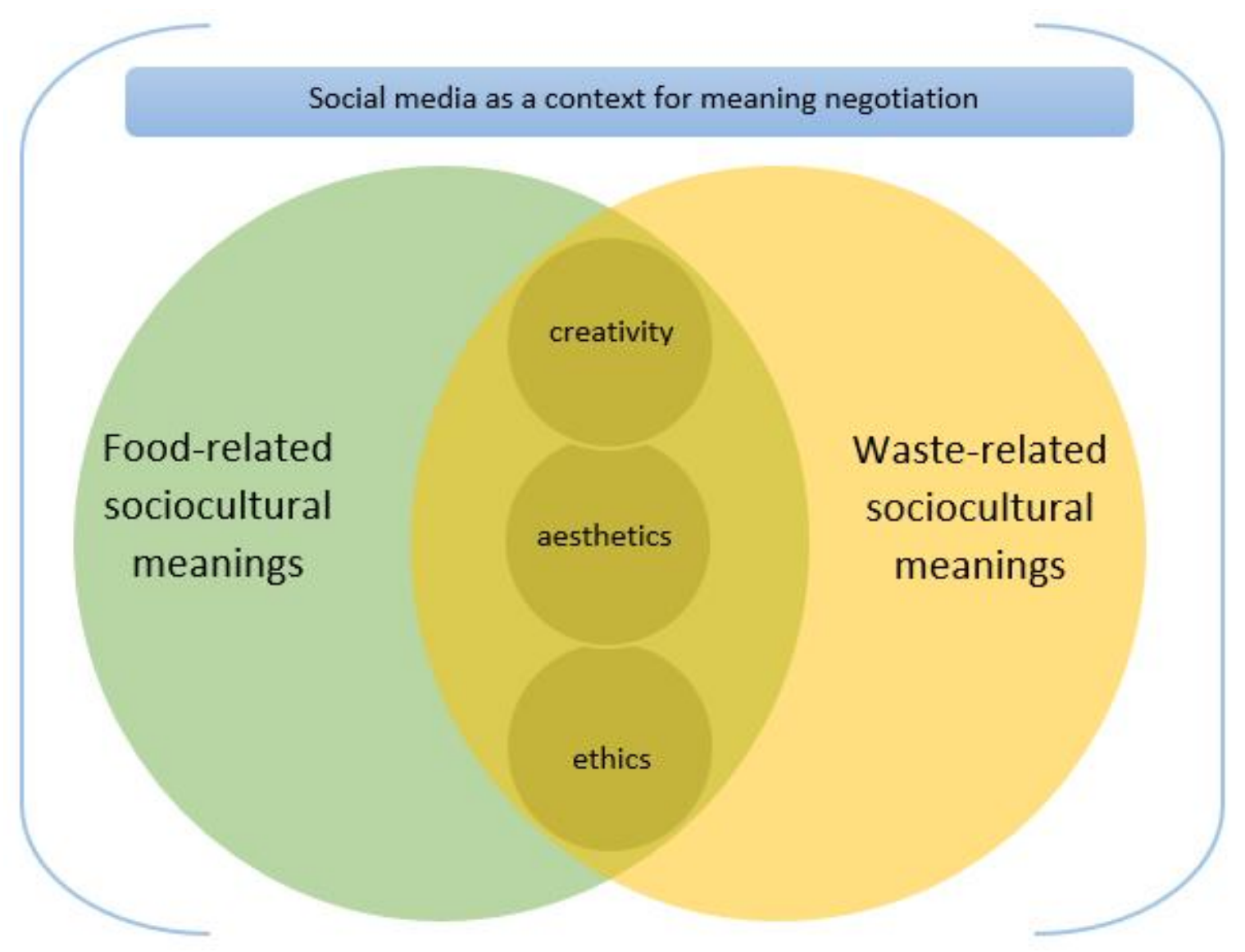

Figure 1. Framework depicting the interrelations of food, waste and social media

Creativity is generally defined as the production of novel, useful ideas or problem solutions (Amabile et al., 2005). Creativity is also part of cooking and food provisioning. For chefs in haute cuisine, creativity intertwines with embodied experience of exploration and exploitation and is often guided by the utilisation of 'free mind' (intuition); this creativity is 'judged' through social recognition by customers or restaurant guides, for instance (Stierand et al., 2014). For ordinary people, kitchen creativity and improvisation is shaped by individual agency and social structure, and through actively creating something new, home cooking in 
everyday life can lead to social change (McCabe and de Waal Malefyt, 2013). Waste can also be a source for creativity, for example when dumpster divers create art by repairing and modifying discarded items (Fernandez et al., 2011). As consumers network through social media communities, individual creativity becomes complemented with various forms of online collective consumer creativity, enabling consumers to create new interpretations and innovations together which would not occur with individual creativity (Kozinets et al., 2008).

Aesthetics denote meanings related to multisensory knowledge and emotions as well as hedonism (Venkatesh and Meamber, 2008). Aesthetic meanings are readily available in the food context, because they entail embodied experiences gained through somatic sensations vision, sound, taste, smell and touch (Joy and Sherry, 2003). Food as potential waste is not as easily associated with positive aesthetic experiences. However, waste can also create positive aesthetic meanings; Hawkins (2001) gave examples of waste education campaigns where organic waste was portrayed as beautiful, 'as an aesthetic of abundance' which involved relation to waste based on enjoyment rather than moral duty (p. 18-19).

Aesthetics play an important role in social media platforms, especially those emphasising visual presentations, such as Instagram. Social media allows for a range of visual presentation opportunities which extend, intensify and alter many forms of visuality (Hand, 2017). Visual aesthetics have become an important aspect of food, especially due to presentations of food on social media platforms such as food blogs (Kozinets et al., 2017). McDonnell (2016) noted that this 'food porn' is 'situated within the twin forces of conspicuous consumption online and food as an art form in the age of digital reproduction' (p. 239). In their study of online food image sharing, Kozinets et al. (2017) emphasised how public (beyond one's own private network) or professional (e.g. food bloggers) sharing of food images on social media made food and eating public and collectively shared.

Ethics connote self-conscious emotions, which drive individuals either to follow or disregard their personal or social standards (Tracy and Robins, 2004). Emotions such as shame and guilt can be considered negative but may be transformed positively through emotions such as pride (ibid.). Issues of sustainable consumption, including practices related to waste, raise ethical concerns, such as feelings of guilt and moral duty, which help create the virtue of managing waste (Hawkins, 2001). Consumers have a collective sense of individual responsibility for sorting rubbish, based on a conscience and commitment to do something for the environment (ibid.).

Food waste conveys judgements about food as waste and waste as food as well as ecological concerns about future well-being. Watson and Meah (2012) found that consumer 
reluctance to waste food was rarely related to global environmental concerns like greenhouse gas emissions. Instead, consumers had a sense of responsibility towards time and money spent on food but also felt responsibility towards food itself, thus having 'an innate resistance to wasting food as an expression of an ethic of thrift' (ibid., p. 117). Blichfeldt et al. (2015), on the other hand, noted that consumers with more altruistic ideologies related to food waste, i.e. ethical reasons and feelings of guilt, seemed to produce less food waste than consumers with more hedonistic ideologies, i.e. not wasting money. Thus, these ethical meanings of sustainable consumption also arise from the role of citizen-consumer, highlighting how consumers should take responsibility for change by making consumption decisions based on sustainability issues as opposed to individual, hedonistic interests (see e.g. Stolle and Micheletti, 2013). By actively trying to reduce food waste, consumers can fulfil their civic duties and thus reduce guilt (see Blichfeldt et al., 2015). However, environmental campaigns relying on moral obligation and duties create negative rather than positive meanings (Aschemann-Witzel et al., 2017; Gjerris and Gaiani, 2013; Hawkins, 2001).

Consumers also negotiate and debate the moral aspects of ethical consumption on social media platforms, shown by previous research, for example, on ethical food consumption (Pecoraro and Uusitalo, 2014) and global travelling (Rokka and Moisander, 2009). The empirical analysis of this paper examines how meanings of food waste reduction related to creativity, aesthetics and ethics were negotiated in social media campaigns.

\section{Methods}

The primary aim of this study was exploratory - to build understanding of an emerging phenomenon of food waste campaigning in social media. Therefore, the research problem was approached with interpretative, qualitative methods. The core focus lies on the content of the social media campaigns and not their ultimate effectiveness, which is a topic for further research. The main strength of qualitative research is to offer rich holistic knowledge of a phenomenon (Silverman, 2006). In line with the interpretive paradigm, this study seeks to understand rather than explain phenomena (Hudson and Ozanne, 1988). In this paradigm, reality is seen as socially constructed and containing multiple viewpoints (Berger and Luckmann, 1984) and social beings as voluntaristic and proactive (Hudson and Ozanne, 1988).

The study utilised qualitative case study methodology (Eisenhardt and Graebner, 2007; Stake, 2005), referring to a research strategy that aims to develop theory though one or multiple case examples. It enabled studying a complex research problem, generating rich research data 
'in situ' and among different 'bounded systems' (campaigns). The case study methodology also enabled the use of different types of data sources (Eisenhardt and Graebner, 2007). However, the qualitative case study method has limitations regarding the findings' generalisability. While it can provide in-depth insights, the findings need further investigation with other methods and a larger sample.

Internet and social media offer a constantly growing source of rich data for researchers, with materials such as blog texts (Haider, 2016; McQuarrie et al., 2013; Schau and Gilly, 2003), online discussion forums (Pecoraro and Uusitalo, 2014) and materials on Facebook groups (Sörum and Fuentes, 2017) as data sources. With the growing awareness of sustainability concerns, an increasing number of campaigns and initiatives around food waste have recently been established (see e.g. Aschemann-Witzel et al., 2017; Secondi et al. 2015). This study utilised three different food waste campaigns as cases of the study, with data collected from different social media platforms.

To select the cases, a theoretical sampling method was used; in other words, cases were chosen on a basis of the opportunity to learn the most (Stake, 2005, 451) and suitability to illustrate the researched phenomenon (Eisenhardt and Graebner, 2007). The cases represented recent Finnish food waste campaigns; Table 1 summarises these cases. All chosen campaigns had certain aspects in common: they targeted consumers directly with the same driving aim to broaden knowledge about food waste and encourage consumers to prevent and reduce it. These campaigns fall into Aschemann-Witzel et al.'s (2017) 'information and capacity building' initiative category. All three campaigns utilised more than one social media platform and originated in Finland (thus representing sociocultural meanings in the same cultural context).

Despite several common characteristics, the three campaigns were also heterogeneous in terms of social media platforms used and their campaign content. Different social media platforms afford different types of activities and content (see also Sörum and Fuentes, 2017). For instance, blogs are personal, diary-like platforms of mostly textual content (Schau and Gilly, 2003), Facebook is more about sharing as well as creating communities of interests and different kinds of projects (Sörum and Fuentes, 2017) and Instagram focuses on visual representations, offering a platform mainly for picture sharing. The bases of the campaigns also varied. In 'From Waste to Delicacy', the initiators were food bloggers (consumers), in 'Waste Week', the initiator was a Finnish non-governmental organisation and in 'Waste Challenge', the initiator was a company. 
Table 1. Case campaigns and the data generated about them.

\begin{tabular}{|c|c|c|}
\hline $\begin{array}{c}\text { CASE } \\
\text { CAMPAIGN }\end{array}$ & $\begin{array}{c}\text { SHORT DESCRIPTION OF } \\
\text { THE CAMPAIGNS }\end{array}$ & DATA \\
\hline $\begin{array}{l}\text { From Waste to } \\
\text { Delicacy }\end{array}$ & $\begin{array}{l}\text { Food bloggers (about } 30 \text { ) } \\
\text { initiated the campaign in their } \\
\text { blogs in } 2012 \text { as a short-term } \\
\text { campaign to raise awareness of } \\
\text { food waste. The campaign tag } \\
\text { has continued to be used in the } \\
\text { participating blogs. }\end{array}$ & $\begin{array}{cl}\text { May } & 2012 \text { - October } 2016 \\
\bullet & 597 \text { blog postings (May } 2012 \text { - August 2016) } \\
\bullet & 7 \text { blogger interviews (October 2016) }\end{array}$ \\
\hline Waste Week & $\begin{array}{l}\text { An annual awareness-raising } \\
\text { campaign organised by a non- } \\
\text { governmental organisation } \\
\text { since } 2013 \text { in Finland. Includes } \\
\text { events, information sharing and } \\
\text { cooperation with participating } \\
\text { actors (companies, associations } \\
\text { etc.). }\end{array}$ & $\begin{array}{l}\text { January } 2016 \text { - September } 2016 \\
\text { - } 331 \text { Instagram pictures } \\
\text { - } 94 \text { Facebook postings } \\
\text { - Food Waste festival (observation September 3, } \\
\quad \text { 2016) }\end{array}$ \\
\hline $\begin{array}{l}\text { Waste } \\
\text { Challenge }\end{array}$ & $\begin{array}{l}\text { A public relations campaign } \\
\text { organised by the largest coffee } \\
\text { house company in Finland to } \\
\text { reduce retailer and household } \\
\text { food waste. }\end{array}$ & $\begin{array}{c}\text { January } 2016 \text { - April } 2017 \\
\text { - } 59 \text { Instagram pictures } \\
\text { - } 10 \text { Facebook postings } \\
\text { - } 16 \text { blog postings } \\
\text { - Campaign's website }\end{array}$ \\
\hline
\end{tabular}

The data was approached as cultural talk (Moisander and Valtonen, 2006), meaning that the authors looked for sociocultural meanings employed in the campaigns to discuss food waste and related practices. According to the study's philosophical positioning, without social interaction, there would not be (any) social reality. Cultural talk, like cultural texts, are social constructions, produced, shared and used in culturally specific, socially organised ways (ibid.). The generated interview data were analysed using the qualitative content analysis method focussing on intensive interpretation (Eriksson and Kovalainen, 2016). Visual data were first collected and then viewed carefully. Then common, repetitive themes were grouped together. Some emerging themes were the same as in the interviews and blog postings, but particularly when analysing sociocultural meanings related to aesthetics, the pictures played an important role. To ensure that the study met general quality criteria for qualitative research, the reliability and consistency of the analysis and interpretation was enhanced by all authors first analysing and interpreting the data separately and then through comparing and combining their perspectives (Silverman, 2006). To clarify the chain of analysis and interpretation for the reader, the paper's results section is supported by verbatim quotations from the data. 


\section{Results and discussion}

Within the themes of creativity, aesthetics and ethics, several sociocultural meanings related to household food waste reduction were identified.

\subsection{Creativity in reducing food waste}

The first meanings identified related to creativity in reducing food waste. Creativity in the campaign data included innovating new recipes based on ingredients, adapting recipes, and creatively using ingredients as well as creatively handling and storing food. The recipe is the foundation in modern cooking, but from the food waste viewpoint, following a recipe to the letter can be problematic, as consumers must have all listed ingredients available. If plans change or the packaging is too large for the recipe, the ingredients can easily become waste. Therefore, to minimise food waste, consumers should be more creative in cooking abandoning an exact plan is desirable.

For example, food bloggers, who can be considered forerunners in creating recipes and tasty food, presented food waste as valuable ingredients. In the blog campaign From Waste to Delicacy, the bloggers discussed the way their skills allowed them to care less about the recipe:

I argue that the biggest reason for food waste is the lack of skills [...] It's a big advantage in reducing food waste, not being dependent on recipes, but being able to adapt. ('From Waste to Delicacy' blogger A, interview)

Hence, the capability to utilise food waste was presented as a specific talent. Creativity was connected to the consumer's experience accumulated through experiment and kitchen improvisation (McCabe and de Waal Malefyt, 2013). This was something food bloggers were more likely to have, because of their general interest in food and cooking. A consumer could act as an artist while creating something beautiful, tasty and useful out of waste that was not conventionally seen as such (Fernandez et al., 2011). Besides acting as artists themselves, the bloggers encouraged readers to create something new out of food waste, to be creative and to adapt recipes. How a recipe was written in the blog was a way to communicate with their audience that food waste was best avoided if recipes were only used as guidance. Some bloggers listed alternative ingredients in their recipes to encourage readers to use what they had instead of buying more: 
Title: 'Don't care about the recipe' You don't (always) need to measure, weigh or count. As long as it's close enough. You taste it. You go with the flow. You create something out of what you have in the food pantry. Whatever you feel like. It's delicious! ('From Waste to Delicacy' blogger B, blog post)

In the Waste Week campaign, meanings of creativity were also prominent. For instance, as part of the campaign, consumers were encouraged to invent and make their own waste-reduction pledge and post it on social media. Consumers promised to stop obeying expiry dates blindly, make new dishes from leftovers and use up all ingredients they bought. These pledges were made by ordinary consumers but also by celebrities and politicians. While the pledges were personal, the pledge content (what was promised) was inspired by information given by the Waste Week campaign related to the main causes of household food waste. Thus, the content created in the campaign was in line with the causes of food waste identified in research (see Hebrok and Boks, 2017). In addition to pictures of food, people posted images containing hints for reducing food waste through innovative and creative storage solutions. In one image, for instance, a consumer bought transparent food containers, explaining that they were new 'weapons' in the war against food waste.

The Waste Challenge campaign was almost entirely based on creative meanings. The campaign, organised by a coffee house, wanted to challenge food bloggers to innovate uses for coffee grounds, among other food waste. The bloggers presented ideas of how they could use coffee grounds as material for homemade cosmetic products such as exfoliator, body scrub, or a cover of grey hair. This campaign also asked consumers to send the best tips and hints for reducing food waste, similar to the Waste Week campaign.

\subsection{Aesthetics of food waste}

Social media with its various applications and sites allows for a range of visual presentation opportunities, enabling the aestheticisation of food waste. In the studied campaigns, this aestheticisation was somewhat similar to 'food porn' (Kozinets et al., 2017; McDonnell, 2016), but in this context, it helped move from negative meanings of food waste as something that looks and tastes bad towards more positive associations. Kozinets et al. (2017) argued that 'food porn' online made 'surrendering to gluttony something to collectively celebrate' (p. 672), increasing consumers' desire to eat. However, in the food waste reduction context, it may be used, for instance, to increase consumers' desire to use leftovers.

In all the campaigns, dishes made of leftovers or ingredients which would otherwise have become waste were portrayed in an aesthetically pleasing way. The photos were colourful 
and styled, the food portrayed in a very well-thought-out manner. Figure 2 represents a collage of example pictures shared on social media by consumers in the campaigns.

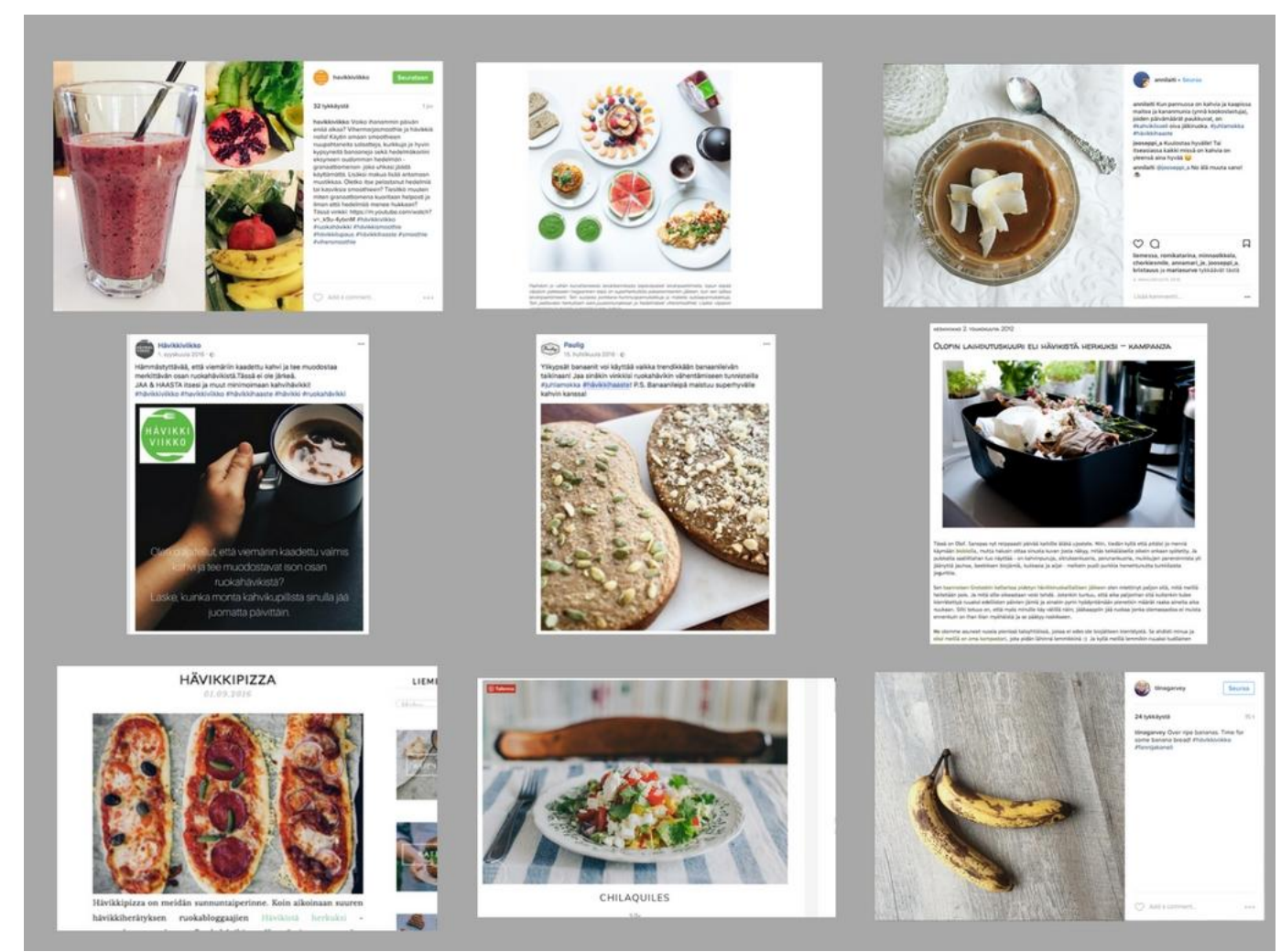

Figure 2. Collage of example pictures related to food waste, shared on social media.

The From Waste to Delicacy blog campaign could be compared to the other posts in food blogs which were not related to the campaign; in many cases, the only thing differentiating campaign posts from regular posts was the 'From Waste to Delicacy' tag. Otherwise, the foods were portrayed in the same way as other recipes on the blog. The bloggers also reported that while they might be amateur chefs, their skills in photography were good, or at least they were interested in constantly developing them.

Another aesthetic theme found in the campaigns was to deliberately present and depict 'ugly things', or things considered waste. These could be purposefully aestheticised and made more beautiful, but the mere presentation of 'waste' in blogs or social media posts could also be considered exceptional. This was because consumers were used to self-expression and identity creation through consumption and material goods. Hence, one could say consumers generally use social media to publicly present their best or desired selves, representing their identity (Schau and Gilly, 2003) and taste (McQuarrie et al., 2013). From this perspective, association with waste by posting a picture of one's bio-waste container, for instance, could be 
considered a radical move. Besides posting beautiful pictures of finished dishes, some consumers both in the From Waste to Delicacy campaign and Waste Week also posted photos of ingredients which were wilted or somewhat spoiled. These were often posted as 'before' and 'after' posts, concretely showing the transformation of the food from 'waste' to 'delicacy'.

Especially in the visual data, such as Instagram postings, food waste was often presented in bright colours. While food waste is often seen as ugly and colourless, like the contents of biodegradable waste containers, in these pictures, the foods, such as smoothies and vegetable soups, had bright colours. One picture posted by the Waste Week portrayed damaged fruits with brown spots, but the outcome had a bright pink colour. Presenting the transformation from repulsive-coloured waste into tasty-looking food challenged this general way of thinking. It visualised the invisible boundary between 'food' and 'waste' that has been found to be decisive in influencing decisions of wasting or not wasting food (Evans, 2012; Watson and Meah, 2012).

Aesthetics involves a multisensory experience, and hence, other elements than the visual dimension are important when constructing aesthetic meanings for food waste (Joy and Sherry, 2003). The senses of taste and smell were also depicted in these campaigns. From Waste to Delicacy blogger described the wonderful taste of food cooked from fish that has been forgotten in the fridge:

I cooked the recipe using the leftover herrings that I bought from Herring Market event, but I presume that similar leftover fish can be found forgotten in many a fridge after Christmas [...] I was totally amazed at how insanely delicious this beetroot-herring casserole finally turned out to be! ('From Waste to Delicacy' blogger F, interview)

However, the technological platform restricted the creation of sensory experiences and meanings, because it is currently not possible to convey tastes and smells of food directly in social media. In some posts, consumers who prepared food from leftovers emphasised the good scents and tastes, because the photograph could not convey the full aesthetic experience. In the Waste Week campaign, associations with aesthetic experience were also promoted by inviting an artist who had made art pieces about food waste to the final event organised by the campaign. The Waste Week campaign also had a range of posters designed by marketing communications professionals, containing tips and information regarding the food waste reduction issue.

The Waste Challenge campaign's initiator company also invited several popular bloggers to participate. They posted visually rich pictures about ways of reducing food waste, similar to bloggers in the From Waste to Delicacy campaign. Many bloggers also shared their 
postings in their own social media accounts, and their readers took part in the campaign by sharing their own pictures, aimed at obtaining a prize offered by the blogger and the company. The Waste Challenge campaign also had a well-developed professional web page which brought this social and environmental food waste campaign to the same visual level as any other marketing material or other campaign pages of the company.

\subsection{Ethics of food waste}

The third meaning identified in the data related to the ethics of food waste. Many bloggers in the From Waste to Delicacy campaign and in interviews explained that the greatest motivation for participation was the moral and ethical perspective related to sustainability problems caused by food waste:

Interviewer: What made you participate in this campaign that focuses on food waste?

Interviewee: I think it is an issue that must be fixed, whether it is household food waste or restaurants and stores, we cannot afford globally to waste as much money to producing food nobody then eats. It is being produced, energy is being used and water is being used and raw ingredients and then it ends up as nothing. I think it is an issue that needs to be revealed and brought forward more. ('From Waste to Delicacy' blogger $\mathrm{G}$, interview)

In the Waste Challenge campaign, the initial plea directed at consumers also referred to their morals, especially denoting traditions of not wasting food which were learnt in childhood:

I was taught already at home that throwing food away is not okay. What you took on your plate, you had to also eat. Did you know that we Finnish people throw away about 400 million kilos of perfectly edible food every year? It means that about $15 \%$ of all food produced goes to the garbage bin. ('Waste Challenge' website, a company representative's tips for reducing food waste)

However, as several researchers suggested, instead of moralising consumer behaviour and appealing to guilt, campaigns should be directed towards more positive ethical meanings (Aschemann-Witzel et al., 2017; Gjerris and Gaiani, 2013; Hawkins, 2001). Consequently, meanings related to ethics in the campaigns also related to the appreciation of food. Bloggers in the From Waste to Delicacy campaign discussed how growing things by themselves as well as cooking the food increased the appreciation of food: 
It [homegrown kale] is more precious than gold to me and it also says something about appreciating food. In part, I think that one way of reducing food waste is to cook the food by yourself. And I mean that the value of food increases when you make an effort, or if the food itself is valuable. ('From Waste to Delicacy' blogger G, interview)

Hence, homegrown food was seen as more inherently valuable than something store-bought. Some pictures with the \#wasteweek hashtag also represented the appreciation of homegrown food products. In these postings, home growing was mentioned in the caption. One photo had a pile of apples on a lawn, the caption indicating that these apples were now being used in different ways in the home kitchen. In another posting, a person also showed an innovative way of turning dry bread into bruschetta, using basil grown on the balcony.

A blogger in the From Waste to Delicacy campaign described how the fact that you could meet and know the people producing the food and could purchase it from them made the food feel more valuable than 'orange protein-filled food packaged in protective gas from a huge supermarket' ('From Waste to Delicacy' blogger F, interview). In other words, there was clearly a hierarchy of less valuable and more valuable foods in terms of moral value. Another blogger described the whole household philosophy being 'positive towards using up waste':

Our family's food philosophy is really positive towards using up waste. Not only are we very frugal with money, we feel almost ashamed to throw away good ingredients or time spent in cooking. Similarly, we learn to use internal organs and those bits of the animal that are not so commonly used. When the animal has been killed to make us food, we think that everything should be used as fully as possible. It is not always gourmet food that is created out of leftovers, but many times the food tastes perfectly good. ('From Waste to Delicacy' blogger C, blog post)

Hence, as Porpino et al. (2016) also suggested, campaigns directed at reducing food waste could focus more on saving money for the family budget by reducing waste, which would perhaps convince consumers in 'caregiver' roles.

I am happy to pay more for quality food, but I compensate by eating out less often and I am really particular about not throwing food in the garbage bin... A family of four could go eight times in the movies, visit an amusement park three times or have a spa holiday once a year with the sum that they waste. (A blogger in her post about food waste, co-operation with the 'Waste Challenge' campaign)

The above quote mentioned another meaning related to family customs in the data. This could be called 'inherited morals', describing how participating consumers and bloggers referred to 
their intention of not wasting food as something they had already learnt in their childhood homes (see also Watson and Meah, 2012):

I have to say that for me personally, the significance of my mum is even greater as kind of a 'conscience', because my mum is perhaps the best killer of food waste ever, I am serious. I don't know anyone else like that. She is in all her wonderful ways almost comical. If she boils carrots, she bakes bread rolls by using that boiling water. Thumbs up for her! [...] The whole waste-reduction issue was not new to me when the 'From Waste to Delicacy Campaign' was launched. It has been an issue in my life since I was zero years old. ('From Waste to Delicacy' blogger G, interview)

An interesting notion from the data was that the ethical aspects were not always clearly evident in the online textual or visual data. Pictures and captions, focussed on the waste food itself, often left out the symbolic meaning of appreciation or ethics of food. However, in the interview data, ethics, food appreciation and 'doing right' represented a big part of interviewees' willingness to fight food waste, and the interviewees mentioned these themes. These themes drove anti-food waste thinking, and through positivity, such as good recipes to avoid food waste, this type of ethical thinking was communicated indirectly without blaming anyone. One blogger explained the beginning of the From Waste to Delicacy campaign:

... I felt that the interest towards the issue [reduction of food waste] increased. [...] I believe in a kind of solution-orientation, that it will not change anything if you write every year that now $\mathrm{X}$ kilos of food goes to waste, because it is largely a question of skills and awareness. Then I thought that if we approach the issue from the positive perspective, that you go out and look for solutions to reduce food waste, practical solutions. ('From Waste to Delicacy' blogger A, interview)

\subsection{Summarising discussion of key findings}

This study's findings revealed the multiplicity of positive meanings related to food waste. Reducing household food waste represented an opportunity to engage in creative consumption practices that aestheticised waste and also foregrounded more positive moral considerations. Hence, the campaigns did not motivate food waste reduction through guilt but rather through more positive affective meanings like appreciation and respect. Table 2 summarises the findings related to each theme. 
Table 2. Summary of findings related to sociocultural meanings of household food waste reduction.

\begin{tabular}{|c|c|}
\hline Theme & Sociocultural meanings related to household food waste reduction \\
\hline Creativity & $\begin{array}{l}\text { - } \quad \text { Creating recipes based on leftover ingredients } \\
\text { - } \text { Adapting recipes } \\
\text { - } \text { Innovativeness in handling and restoring food } \\
\text { - } \text { Creating something completely new from food waste }\end{array}$ \\
\hline Aesthetics & $\begin{array}{l}\text { - } \quad \text { Beautiful visual presentations of leftover food } \\
\text { - } \quad \text { Aesthetic visual presentations of 'ugly things' } \\
\text { - Highlighting senses of taste to food } \\
\text { - }\end{array}$ \\
\hline Ethics & $\begin{array}{l}\text { - } \text { Appreciation of food } \\
\text { - } \text { Childhood traditions } \\
\text { - } \\
\text { - } \\
\text { Soing the 'right thing the } \\
\text { Suinability and the responsibility to take care of the environment }\end{array}$ \\
\hline
\end{tabular}

Even though this study did not focus on evaluating the effects of social media campaigns for household food waste reduction, it still has important insights to offer. Waste is not usually discussed or shown on social media platforms (cf. Comber and Thieme, 2013). However, online environments may provide new arenas for environmental dialogue which help create new, more sustainable consumption practices and active citizenship (Rokka and Moisander, 2009).

Social media platforms enable making the private public and the invisible visible, for instance through shared images of everyday life. The blog medium has been theorised in previous research as a way for consumers to build both social and cultural capital and act as taste leaders (McQuarrie et al., 2013). This notion was complemented by adding that bloggers and other opinion leaders, for instance on Instagram, may also operate as consumer-citizens inspiring others to change towards more sustainable consumption practices. Also, Rettie et al. (2014) suggested that showing celebrities and authority figures performing some behaviour could be effective in positioning some types of sustainable consumption behaviour as normal.

One specific feature in each studied campaign was consumers' ability to participate in the discussion. The power of transforming consumers' consumption patterns was thereby moved from experts (who traditionally lead campaigns) to consumers, representing a bottomup rather than top-down orientation. Rather than communicating about food waste reduction in a monologue from sender to receiver, social media allowed people to post their own ideas and comments and visualise how they actually approached the phenomenon in their everyday lives. 
In social media, new symbols, such as campaign hashtags on Twitter or tags in blogs, gathered together positive meanings related to food waste. Haider (2016) argued that hashtags could cross-connect content produced on different social media platforms and make it easier to find and create a sense of community around the sustainability issue. Similarly, hashtags used for the case campaigns helped people join the conversation. Furthermore, people could choose where they wanted to participate in the dialogue, for instance on the firms' or campaigns' websites, on their favourite food blog or in their own Instagram account. This resulted in a truly cooperative, shared communication method.

\section{Conclusions}

The study's objective was to investigate how sociocultural meanings of household food waste reduction were (re)negotiated in social media campaigns. The study identified three themes of sociocultural meaning used in three campaigns directed at reducing household food waste. All themes shared a positive orientation towards the issue; creativity, aesthetics and ethics of food waste included meanings that positively represented food waste reduction. The results suggested that focusing on positive aspects of reducing waste was one way to approach this sustainability issue. This perspective shifted the focus from individuals to broader sociocultural meanings of food waste.

While previous research on the food waste issue has focussed largely on determining the causes and contexts of this problem, this study's findings shed light on possible solutions. Due to the nature of the data and the focus on sociocultural meanings, however, findings cannot be generalised without reservations. Thus, further research is needed to prove the success and/or impact of similar campaigns on consumers' behaviour. Also, the study was conducted in Finland; hence, geographical location and cultural differences might have highlighted certain types of sociocultural meanings. Given these limitations, further research could, for instance, explore the actual effects of social media campaigns in the volume and nature of food waste through different methodologies, contradictions and/or negative meanings related to sociocultural meanings, or whether social media can be used to address other sustainability challenges. A potential avenue for future research could also involve looking at different campaigns from a network perspective, focusing on different actors and their roles in the network as well as how this network changes over time. 


\section{Acknowledgments}

This study is part of the WASTEBUSTERS research project examining consumer-citizens as active participants in food waste reduction, funded by Emil Aaltonen Foundation, Finland, 2016-2019.

\section{References}

Amabile, T.M., Barsade, S.G., Mueller, J.S., Staw, B.M., 2005. Affect and creativity at work. Administrative Sci. Q., 50, 367-403.

Arnould, E.J., Thompson, C.J., 2005. Consumer culture theory (CCT): Twenty years of research. J. Consum. Res. $31,868-882$.

Aschemann-Witzel, J., de Hooge, I., Amani, P., Bech-Larsen, T., Oostindjer, M., 2015. Consumer-related food waste: causes and potential for action. Sustainability 7, 6457-6477.

Aschemann-Witzel, J., de Hooge, I.E., Rohm, H., Normann, A., Bossle, M.B., Grønhøj, A., Oostindjer, M., 2017. Key characteristics and success factors of supply chain initiatives tackling consumer-related food waste-A multiple case study. J. Clean. Prod. 155, 33-45.

Berger, P.L., Luckmann, T., 1984 [1966]. The social construction of reality: A treatise in the sociology of knowledge. Penguin, Harmondsworth.

Bernstad, A., 2014. Household food waste separation behavior and the importance of convenience. Waste Manag. 34, 1317-1323.

Blichfeldt, B.S., Mikkelsen, M., Gram, M., 2015. When it stops being food: The edibility, ideology, procrastination, objectification and internalization of household food waste. Food, Culture \& Soc. 18, 89105.

Burchell, K., Rettie, R., Patel, K., 2013. Marketing social norms: social marketing and the 'social norm approach'. J. Consumer Behav. 12, 1-9.

Chaykowski, K., 2017. Mark Zuckerberg: 2 Billion Users Means Facebook's 'Responsibility Is Expanding'. Forbes, 27 June 2017. https://www.forbes.com/sites/kathleenchaykowski/2017/06/27/facebook-officiallyhits-2-billion-users/\#1101b1537080 (accessed 18 December 2017).

Cherrier, H., 2005. Using existential-phenomenological interviewing to explore meanings of consumption, in: Harrison, R., Newholm, T., Shaw, D. (Eds.), The Ethical Consumer. Sage, Wiltshire, pp. 125-135.

Comber, R., Thieme, A., 2013. Designing beyond habit: opening space for improved recycling and food waste behaviors through processes of persuasion, social influence and aversive affect. Pers. Ubiquitous. Comput. 17, 1197-1210.

Eisenhardt, K.M., Graebner, M.E., 2007. Theory building from cases: Opportunities and challenges. Acad. Manag. J. 50, 25-32.

eMarketer 2017. eMarketer Updates Worldwide Social Network User Figures. 17 June 2017. https://www.emarketer.com/Article/eMarketer-Updates-Worldwide-Social-Network-UserFigures/1016178 (accessed 31 January 2018).

Eriksson, P., Kovalainen, A., 2016. Qualitative Methods in Business Research, second ed. Sage, London.

European Commission, 2016. Reducing food waste: the EU's response to a global challenge. European Commission Fact Sheet. 28 November 2016. http://europa.eu/rapid/press-release_MEMO-16-3989_en.htm (accessed 05 February 2018).

Evans, D., 2011. Blaming the consumer-once again: The social and material contexts of everyday food waste practices in some English households. Crit. Public Health 21, 429-440.

Evans, D., 2012. Beyond the throwaway society: Ordinary domestic practice and a sociological approach to household food waste. Soc. 46, 41-56.

Fernandez, K.V., Brittain, A.J., Bennett, S.D., 2011. "Doing the duck": negotiating the resistant-consumer identity. Eur. J. Mark. 45, 1779-1788.

Gjerris, M., Gaiani, S., 2013. Household food waste in Nordic countries: Estimations and ethical implications. Nord. J. Appl. Ethics 7, 6-23.

Graham-Rowe, E., Jessop, D.C., Sparks, P., 2014. Identifying motivations and barriers to minimising household food waste. Resour. Conserv. Recy. 84, 15-23.

Grainger, M.J., Stewart, G.B., 2017. The jury is still out on social media as a tool for reducing food waste a response to Young et al. (2017). Resour. Conserv. Recycl. 122, 407-410.

Haider, J., 2016. The shaping of environmental information in social media: Affordances and technologies of selfcontrol. Environ. Commun. 10, 473-491.

Hall, S. (Ed.), 1997. Representation: Cultural Representations and Signifying Practices. Vol. 2. Sage, London. 
Hand, M., 2017. Visuality in social media: Researching images, circulations and practices, in: Sloan, L., QuanHaase, A. (Eds.), The SAGE Handbook of Social Media Research Methods. Sage, London, pp. 215-231.

Hanssen, O.J., Syversen, F., Stø, E., 2016. Edible food waste from Norwegian households-Detailed food waste composition analysis among households in two different regions in Norway. Resour. Conserv. Recy. 109, $146-154$.

Hawkins, G., 2001. Plastic bags: living with rubbish. Int. J. Cult. Stud. 4, 5-23.

Hebrok, M., Boks, C., 2017. Household food waste: Drivers and potential intervention points for design-An extensive review. J. Clean. Prod. 151, 380-392.

Hudson, L.A., Ozanne, J.L., 1988. Alternative ways of seeking knowledge in consumer research. J. Consum. Res. 14, 508-521.

Joy, A., Sherry, J.F., 2003. Speaking of art as embodied imagination: A multisensory approach to understanding aesthetic experience. J. Consum. Res. 30, 259-282.

Jörissen, J., Priefer, C., Bräutigam, K.R., 2015. Food waste generation at household level: Results of a survey among employees of two European research centers in Italy and Germany. Sustainability 7, 2695-2715.

Kaplan, A.M., Haenlein, M., 2010. Users of the world, unite! The challenges and opportunities of social media. Bus. Horiz. 53, 59-68.

Katajajuuri, J.M., Silvennoinen, K., Hartikainen, H., Heikkilä, L., Reinikainen, A., 2014. Food waste in the Finnish food chain. J. Clean. Prod. 73, 322-329.

Koivupuro, H.K., Hartikainen, H., Silvennoinen, K., Katajajuuri, J.M., Heikintalo, N., Reinikainen, A., Jalkanen, L., 2012. Influence of socio-demographical, behavioural and attitudinal factors on the amount of avoidable food waste generated in Finnish households. Int. J. Consum. Stud. 36, 183-191.

Korda, H., Itani, Z., 2013. Harnessing social media for health promotion and behavior change. Health Promot. Pract. 14, 15-23.

Lovejoy, K., Saxton, G. D., 2012. Information, community, and action: How nonprofit organizations use social media. J. Comput. Mediat. Commun. 17, 337-353.

Kozinets, R., Hemetsberger, A., Schau, H.J., 2008. The wisdom of consumer crowds: Collective innovation in the age of networked marketing. J. Macromarketing 28, 339-354.

Kozinets, R., Patterson, A., Ashman, R., 2017. Networks of desire: How technology increases our passion to consume. J. Consumer Res. 43, 659-682.

McCabe, M., de Waal Malefyt, T., 2013. Creativity and cooking: Motherhood, agency and social change in everyday life. J. Consum. Cult. 15, 48-65.

McDonnell, E.M., 2016. Food Porn: The Conspicuous Consumption of Food in the Age of Digital Reproduction, in: Bradley P. (Ed.) Food, Media and Contemporary Culture. Palgrave Macmillan, London, pp. 239-265.

McQuarrie, E.F., Miller, J., Phillips, B. J., 2013. The megaphone effect: Taste and audience in fashion blogging. J. Consum. Res. 40, 136-158.

Moisander, J., Valtonen, A., 2006. Qualitative Marketing Research: A Cultural Approach. Sage, London.

Mourad, M., 2016. Recycling, recovering and preventing "food waste": competing solutions for food systems sustainability in the United States and France. J. Clean. Prod. 126, 461-477.

Parizeau, K., von Massow, M., Martin, R., 2015. Household-level dynamics of food waste production and related beliefs, attitudes, and behaviours in Guelph, Ontario. Waste Manage. 35, 207-217.

Parfitt, J., Barthel, M., Macnaughton, S., 2010. Food waste within food supply chains: quantification and potential for change to 2050. Philos. Trans. R. Soc. Lond. B Biol. Sci. 365, 3065-3081.

Pearson, E., Tindle, H., Ferguson, M., Ryan, J., Litchfield, C., 2016. Can we tweet, post, and share our way to a more sustainable society? A review of the current contributions and future potential of \#socialmediaforsustainability. Annu. Rev. Environ. Resour. 41, 363-397.

Pecoraro, M.G., Uusitalo, O., 2014. Conflicting values of ethical consumption in diverse worlds - A cultural approach. J. Consumer Cult., 14, 45-65.

Porpino, G., Parente, J., Wansink, B., 2015. Food waste paradox: antecedents of food disposal in low income households. Int. J. Consum. Stud. 39, 619-629.

Porpino, G., Wansink, B., Parente, J., 2016. Wasted positive intentions: The role of affection and abundance on household food waste. J. Food Prod. Mark. 22, 733-751.

Principato, L., Secondi, L., Pratesi, C.A., 2015. Reducing food waste: an investigation on the behaviour of Italian youths. Brit. Food J. 117, 731-748.

Qi, D., Roe, B.E., 2016. Household food waste: Multivariate regression and principal components analyses of awareness and attitudes among US consumers. PloS One, 11. http://dx.doi.org/10.1371/journal.pone.0159250 (accessed 21 November 2016).

Rettie, R., Burchell, K., Barnham, C., 2014. Social normalisation: Using marketing to make green normal. J. Consum. Behav. 13, 9-17.

Ridoutt, B.G., Juliano, P., Sanguansri, P., Sellahewa, J., 2010. The water footprint of food waste: case study of fresh mango in Australia. J. Clean. Prod. 18, 1714-1721. 
Rokka, J., Moisander, J., 2009. Environmental dialogue in online communities: negotiating ecological citizenship among global travellers. Int. J. Consum. Stud. 33, 199-205.

Secondi, L., Principato, L., Laureti, T., 2015. Household food waste behaviour in EU-27 countries: A multilevel analysis. Food Policy 56, 25-40.

Schau, H.J., Gilly, M.C., 2003. We are what we post? Self-presentation in personal web space. J. Consum. Res. $30,385-404$.

Silverman, D., 2006. Interpreting qualitative data, third ed. Sage, London.

Stake, R.E., 2005. Qualitative case studies, in: Denzin, N.K., Lincoln, Y.S. (Eds.), The Sage Handbook of Qualitative Research: Third Edition. Sage, Thousand Oaks, pp. 443-466.

Stancu, V., Haugaard, P., Lähteenmäki, L., 2016. Determinants of consumer food waste behaviour: Two routes to food waste. Appetite 96, 7-17.

Stefan, V., Van Herpen, E., Tudoran, A.A., Lähteenmäki, L., 2013. Avoiding food waste by Romanian consumers: The importance of planning and shopping routines. Food Qual. Prefer. 28, 375-381.

Stierand, M., Dörfler, V., MacBryde, J., 2014. Creativity and innovation in haute cuisine: Towards a systemic model. Creat. Innov. Manage. 23, 15-28.

Stolle, D. \& Micheletti, M., 2013. Political consumerism: Global responsibility in action. Cambridge University Press, New York.

Sörum, N., \& Fuentes, C., 2017. "Write something": The shaping of ethical consumption on Facebook, in: Cochoy, F., Hagberg, J., Petersson McIntyre, M., Sörum, N. (Eds.), Digitalizing Consumption: How Devices Shape Consumer Culture. Routledge, Abingdon, pp. 144-166.

Tracy, J.L., Robins, R.W., 2004. Putting the self into self-conscious emotions: A theoretical model. Psychol Inq. $15,103-125$.

Venkatesh, A., Meamber, L.A., 2008. The aesthetics of consumption and the consumer as an aesthetic subject. Consum. Mark. Cult. 11, 45-70.

Visschers, V.H., Wickli, N., Siegrist, M., 2016. Sorting out food waste behaviour: A survey on the motivators and barriers of self-reported amounts of food waste in households. J. Environ. Psychol. 45, 66-78.

Watson, M., Meah, A., 2012. Food, waste and safety: Negotiating conflicting social anxieties into the practices of domestic provisioning. Soc. Rev. 60, 102-120.

Young, W., Russell, S.V., Robinson, C.A., Barkemeyer, R., 2017. Can social media be a tool for reducing consumers' food waste? A behaviour change experiment by a UK retailer. Resour. Conserv. Recycl. 117, 195-203. 